\title{
FEATURES OF MICROWAVE FIRED UTILITARIAN STONEWARE
}

\author{
T. Santos ${ }^{1,2}$, N. F. Santos ${ }^{2}$, C. S. F. Gomes ${ }^{3}$, L. Hennetier ${ }^{4}$, V. A. F. Costa ${ }^{1}$, L. C. Costa ${ }^{2}$ \\ 1 Centre for Mechanical Technology and Automation, Department of Mechanical \\ Engineering, University of Aveiro, 3810-193 Aveiro, Portugal \\ ${ }^{2}$ I3N and Department of Physics, University of Aveiro, 3810-193 Aveiro, Portugal \\ ${ }^{3}$ GeoBioTec, Research Unit of FCT, University of Aveiro, 3810-193 Aveiro, Portugal \\ ${ }^{4}$ Technological Centre for Ceramic and Glass Industries, 3025-307 Coimbra, Portugal \\ tiago.santos@ua.pt
}

Keywords: microwave heating, stoneware, microstructure, SEM, XRD, water absorption.

\begin{abstract}
Both high temperature phases and microstructure transformations of stoneware products microwave and conventionally (gas and electric) fired are investigated aiming at a better understanding of factors affecting their mechanical and aesthetic properties. The microstructure of microwave fired stoneware has similar characteristics to those of conventionally fired samples, microwave firing requiring lower temperatures to achieve a similar structure. X-Ray diffraction and scanning electron micrographs show that the most relevant transformations are complete for lower temperatures when using microwave heating. Microwave radiation is presented as an alternative heating technology for stoneware firing, leading to similar, or even better, mechanical properties and similar microstructural characteristics, requiring lower firing temperatures and shorter processing times.
\end{abstract}

\section{Introduction}

Stoneware, such as porcelain and other clay-based materials, is a composite material consisting of a glass matrix that embraces two main crystalline phases, quartz and mullite. It is a ceramic material, usually produced through a single firing stage at temperatures close to $1200{ }^{\circ} \mathrm{C}[1,2]$. Like porcelain, it can be double fired, through a first firing stage at 1000 ${ }^{\circ} \mathrm{C}$ followed by the firing of the glazed body at $1325^{\circ} \mathrm{C}[3]$. The firing temperatures depend on the constituent raw materials, which can have significant variations: $30-40 \%$ of clay, 5 $-20 \%$ of quartz and $45-55 \%$ of feldspars. Secondary minerals such as flint, talc and zircon may be added to lower the melting temperature and to increase the whiteness of the finished product $[1,2,4]$. It is a product normally colored, presenting some impurities like hematite, goethite, maghemite, lepidocrocite, the purity of the raw materials being not so crucial as for porcelain $[4,5]$.

The stoneware industry is highly hydrocarbons dependent, natural gas being the most used primary energy source for products drying and firing. Searching for a more decarbonized industry, microwave radiation is presented as an alternative heating technology, which shows to be a more environmentally friendly firing method for a wide variety of ceramic materials $[6,7]$. 


\section{Experimental methodology- Firing}

Samples were fired in both microwave and electric furnaces at temperatures of 500, 800, $1000,10501100,1140,1180,1225$ and $1300{ }^{\circ} \mathrm{C}$. The heating cycles, from room to maximum temperature, were processed from 40 up to 75 minutes. The cooling phase depends on the thermal inertia of each furnace. Results were compared with a reference, corresponding to the average of a set of 10 mugs fired in the tunnel kiln of Grestel Company at $\sim 1200{ }^{\circ} \mathrm{C}$ in 200 minutes. One test was carried out in the microwave furnace using a firing cycle of 115 minutes.

Microwave furnace: Samples were fired in a 6 magnetrons multimode furnace, each one operating with a nominal power of $900 \mathrm{~W}$ at a frequency of $2.45 \mathrm{GHz}$. A pyrometer and a thermocouple were installed in the microwave furnace for temperature measurement, monitoring and control. Calibration of the pyrometer was made in an electric furnace for more accurate temperature measurements. The thermocouple used in the microwave furnace was temporarily installed in the electric furnace, presenting a temperature difference of the order of 2 to $5{ }^{\circ} \mathrm{C}$ when comparing with that indicated by the electric furnace thermocouple. The microwave firing process was automated through the development of a Labview program searching for homogeneous heating, by creating a sequence of combined permutations of the magnetrons operating at a given moment of the heating process. The system operates in a Microwave Hybrid Heating ( $\mathrm{MHH}$ ) mode [8], as it uses a SiC plate acting as the base for the stoneware mugs and as a microwave susceptor. For lower temperatures, the material is heated indirectly, due to the heat released from the susceptor. After reaching its critical temperature, the stoneware absorbs the microwave radiation efficiently and is directly heated by the absorption of the microwave radiation [9].

The interior of the microwave furnace has a sandwich insulating wall, with $75 \mathrm{~mm}$ thickness. The layout displaying the distribution of the mugs over the $\mathrm{SiC}$ plate, inside the microwave furnace, is shown in Fig. 1.

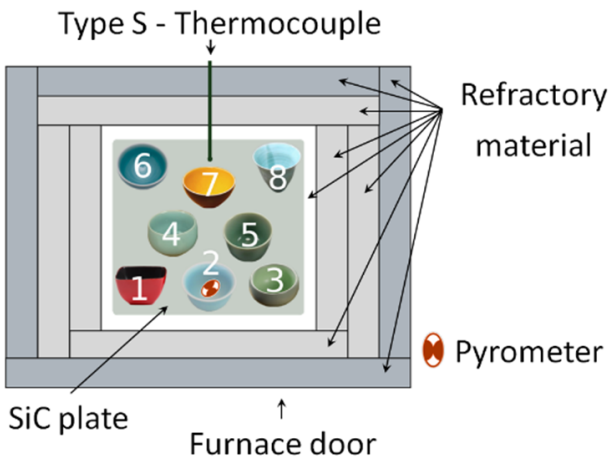

Fig. 1. Mugs distribution inside the microwave furnace. 
Electric furnace: The electric furnace is a standard furnace with a nominal power of 4.5 $\mathrm{kW}$. Due to the reduced availability of the samples' material and the reduced size of the electric furnace, only an aliquot taken from stoneware mugs was electrically fired. The temperature during the firing process was measured by the electric furnace thermocouple.

\section{Employed techniques and analysed features}

Rupture energy analysis: Stoneware mugs were tested by impact at the rim, according to ASTM 368/ISO 12980. Samples were repeatedly impacted increasing hammer's energy until fracture occurrence [10]. Results are presented in Fig. 2.

Water absorption analysis: Water absorption was determined based on the mass of aliquots samples impregnated with boiling water, following the porcelain tableware standard (BS5416) [11]. Aliquots were drawn from two different parts (the base and the rim) of the mugs. Results are presented in Fig. 2.

Simultaneous Thermo Analysis (STA): Differential Scanning Calorimetry (DSC) and ThermoGravimetry Analyses (TGA) were performed on stoneware powder from room temperature up to $1250{ }^{\circ} \mathrm{C}$. Some of the transformations occurring in the stoneware during firing were studied and results compared with those found in the literature. Results are presented in Fig. 3.

Optical microscopy analysis: Olympus $\mathrm{BH} 2$ optical microscope was used to perform microstructure (closed porosity) analysis. Prior to optical analysis, stoneware aliquots were grinded with sandpaper and water, and subjected to a final polishing with a $1 \mu \mathrm{m}$ ultra pure alumina suspension. Results are presented in Fig. 4.

Scanning Electron Microscopy (SEM - EDS) analysis: After optical analysis the aliquots were etched with a $10 \% \mathrm{HF}$ solution during $60 \mathrm{~s}$, then carbon coated and analyzed using the TESCAN-Vega 3 SBM SEM instrument. Results are presented in Fig. 5.

X-Ray diffraction (XRD) analysis: For detection of the phases present during firing, the powder aliquots of the samples fired at different temperatures, including green and gas fired references, were analyzed by powder X-Ray Diffraction (XRD). Data were collected using Empyrean Panalytical Diffractometer ( $\mathrm{CuK} \alpha$ radiation) with a Ni filter. Intensity data of diffraction peaks were provided by the continuous counting method in the range of $5^{\circ}$ to $80^{\circ}$ of $2 \theta$ angles. Results are presented in Fig. 6.

\section{Results}

The rupture energy and the water absorption determined on aliquots drawn from mugs rim and from mugs base are presented in Fig. 1. The rupture energy of the reference is over the curve of the microwave fired samples. Aliquots taken from the base of microwave fired mugs show lower water absorption than the reference. Aliquots taken from the rim of microwave fired mugs provided results contradicting the results corresponding to the basal ones. Comparing results with those of the electrically fired samples, it is clear that microwave fast fired samples present characteristics closer to that of the reference than the 
electrically fired ones, Table 1 . At $1180{ }^{\circ} \mathrm{C}$ the electrically fired samples provide water absorptions values of $7.5 \%$, much higher than the water absorption obtained for microwave fired and reference samples. The firing test with a 115 minutes cycle (marked in Fig. 1 in green) did not present significant differences when compared to the samples fired in 70 minutes cycles, the rupture energy being lower for this case.

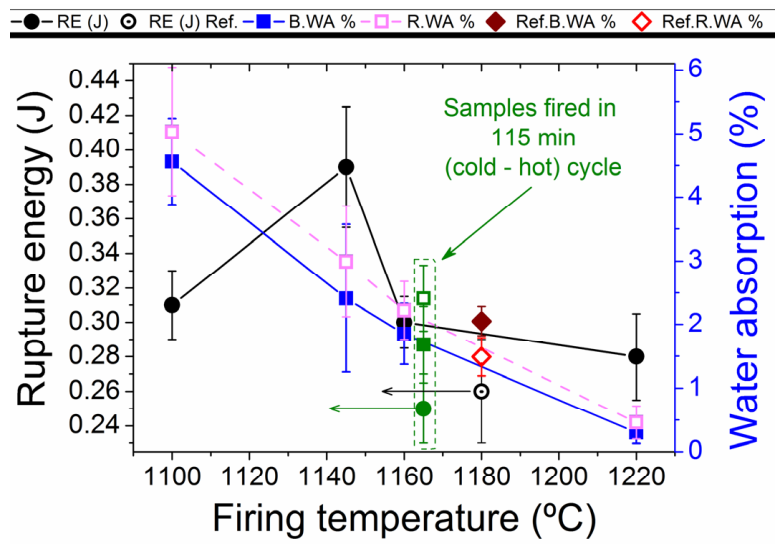

Fig. 2. Rupture energy (RE (J)) and water absorption (WA \%) as a function of the firing temperature (measured by the pyrometer). Ref. refers to the reference samples. B.WA\% refers to the water absorption of aliquots from the mugs base. R.WA\% refers to the water absorption of aliquots from the mugs rim.

Table 1. Water absorption of aliquots fired in the electric furnace.

\begin{tabular}{cc}
\hline Temperature $\left({ }^{\circ} \mathrm{C}\right)$ & Water Absorption $(\%)$ \\
\hline 1100 & 18.6 \\
1140 & 10.3 \\
1180 & 7.5 \\
1225 & 2.9 \\
1300 & 0.2 \\
\hline
\end{tabular}

Differential Scanning Calorimetry (DSC) and ThermoGravimetry (TG) analyses presented in Fig. 3, show that the loss of free and bound water represent about $1.8 \%$ of the total weight loss. Below $450{ }^{\circ} \mathrm{C}$ and under oxidizing conditions [12], burning of organic matter may occur, mainly in less pure clays. This could explain the continuous TG decrease, associated also to the continuous release of water from the stoneware raw materials. It is followed by the release of structural water from kaolinite leading to the formation of metakaolinite, endothermic reaction expressed by a peak at $510{ }^{\circ} \mathrm{C}$. The onset of the kaolinite structure collapse is observable from $\sim 450^{\circ} \mathrm{C}$ upwards, which according to [13] might extend up to temperatures close to $1000{ }^{\circ} \mathrm{C}$. This transformation comprises a weight loss of $5.6 \%$. The $\alpha \rightarrow \beta$ transformation of quartz occurs at $573{ }^{\circ} \mathrm{C}$ [4]. The pre-mullite and liquid phase formations occur at approximately $990^{\circ} \mathrm{C}$ and $1100^{\circ} \mathrm{C}$, respectively $[2,4]$. Formation of the liquid phase lowers to the eutectic temperature of $985^{\circ} \mathrm{C}$ [14], or of $990 \pm 20^{\circ} \mathrm{C}$ according to [15], for the $\mathrm{K}_{2} \mathrm{O}-\mathrm{Al}_{2} \mathrm{O}_{3}-\mathrm{SiO}_{2}$ system. 
The residual quartz, which is part of the initial composition, only reacts with the liquid phase at higher temperatures, beginning to be dissolved for temperatures above $1200{ }^{\circ} \mathrm{C}[4,14]$.

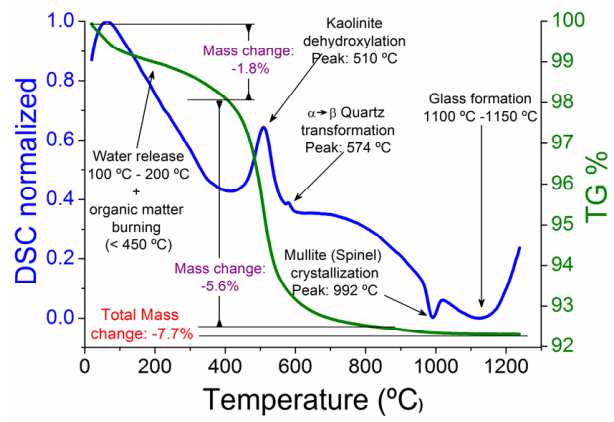

Fig. 3. Differential Scanning Calorimetry (DSC) and ThermoGravimetry (TG) curves of dry stoneware raw materials composition.

At temperatures close to $990{ }^{\circ} \mathrm{C}$ mullite is formed due to a solid state reaction consisting of a rearrangement of the constituents, silica and alumina, released from metakaolinite. Above $1200{ }^{\circ} \mathrm{C}$ recrystallization occurs, with the consequent development of mullite crystals exhibiting needles' shape. With the dissolution of quartz the liquid phase content increases and its viscosity decreases, having an enhanced effect on the growth of mullite crystals [4,16]. In Fig. 4 the set of images show the microstructures of aliquots of several samples fired between $1000{ }^{\circ} \mathrm{C}$ and $1300{ }^{\circ} \mathrm{C}$ in both the microwave (MW) and electric (E) furnaces. The gas fired reference is also shown for comparison.

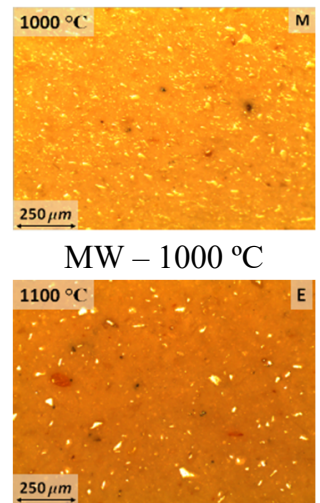

$\mathrm{E}-1100^{\circ} \mathrm{C}$

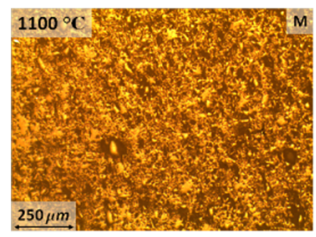

$\mathrm{MW}-1100^{\circ} \mathrm{C}$

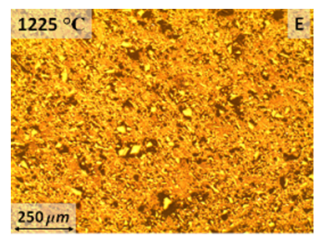

$\mathrm{E}-1225^{\circ} \mathrm{C}$

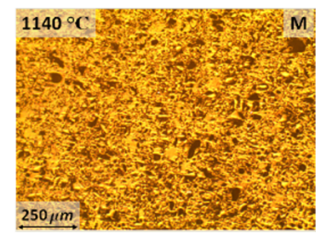

$\mathrm{MW}-1140{ }^{\circ} \mathrm{C}$

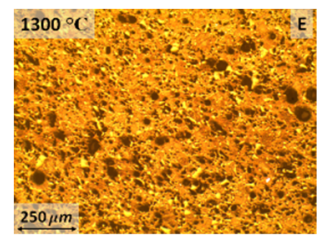

$\mathrm{E}-1300^{\circ} \mathrm{C}$

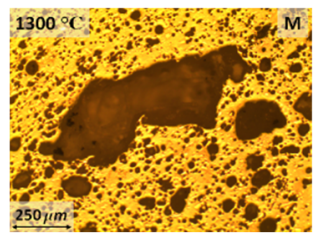

$\mathrm{MW}-1300^{\circ} \mathrm{C}$

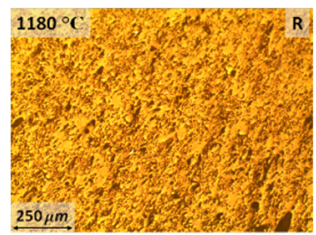

Gas Ref. $-1180^{\circ} \mathrm{C}$

Fig. 4. Optical microscope images of samples microwave fired (M), electrically fired (E) and gas fired (Gas Ref.) at several temperatures.

From Fig. 4 the microwave fired samples, in fast cycles of $70 \mathrm{~min}$ or less, have a more developed microstructure that those electrically fired, microwave fired samples at $1140{ }^{\circ} \mathrm{C}$ already presenting features very similar to those of the reference. The electrically fired samples at this same temperature have an underdeveloped microstructure, the sample fired at $1225^{\circ} \mathrm{C}$ being closer to the reference. For a better and deeper understanding of the main 
reasons for the observations made so far, SEM observations were carried out (Fig. 5). At $1050^{\circ} \mathrm{C}$ an advanced state of melting and dissolution could be observed in feldspar grains from samples fired in the microwave furnace. This melting and dissolution is just incipient in the electrically fired samples, which still present structures/agglomerates of platy particle relics derived from kaolinite structural collapse, and that are just starting transformation to mullite. At $1140{ }^{\circ} \mathrm{C}$ the mullite is more developed in the microwave fired samples than in the electrically fired ones, already presenting mullite type-II, yet not so developed as in the reference sample.
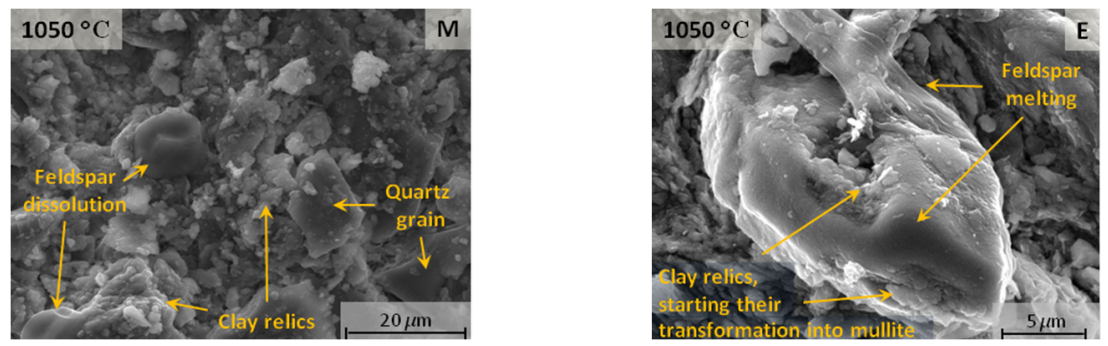

Microwave (left) and electrically (right) fired samples at $1050{ }^{\circ} \mathrm{C}$
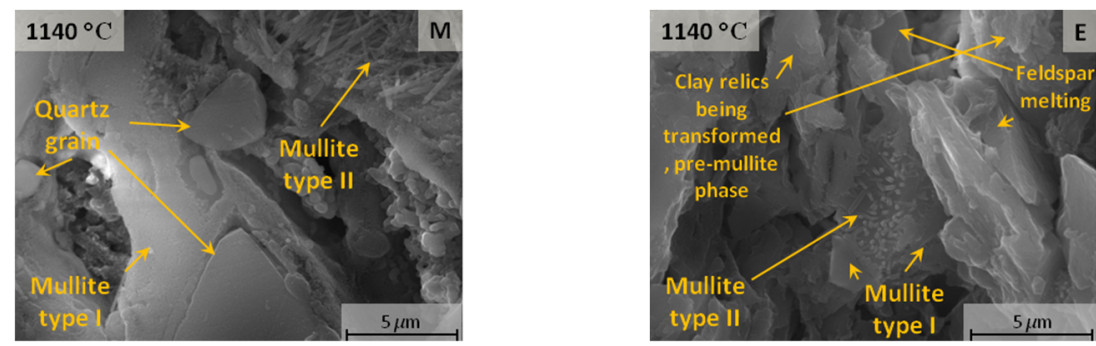

Microwave (left) and electrically (right) fired samples at $1140^{\circ} \mathrm{C}$

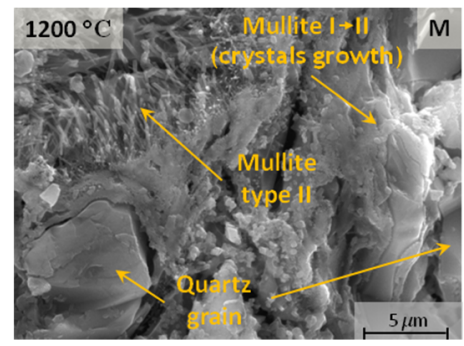

$\mathrm{MW}-1200{ }^{\circ} \mathrm{C}$

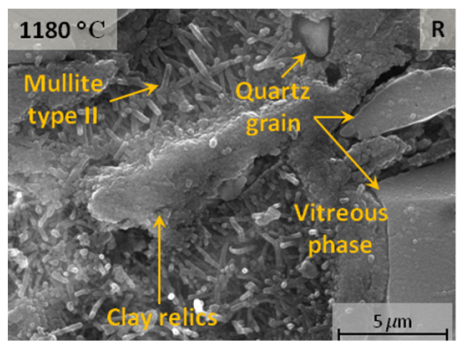

Gas Ref. $-1180^{\circ} \mathrm{C}$

Fig. 5. SEM images of microwave fired, electrically fired and gas fired reference samples, fired at $1050{ }^{\circ} \mathrm{C}, 1140^{\circ} \mathrm{C}, 1180{ }^{\circ} \mathrm{C}$ and $1200^{\circ} \mathrm{C} .(\mathrm{M})=$ Microwave; $(\mathrm{E})=$ Electrically; $(\mathrm{R})=$ Gas reference.

The results of the XRD analysis presented in Fig. 6 show that the electrically fired samples exhibit less intense mullite peaks than those microwave fired at the same temperature, the diffractograms of microwave fired samples at $1140{ }^{\circ} \mathrm{C}$ being very similar to the one of the reference sample. XRD results also show that some transformations occur earlier, i.e., for lower temperatures, in the case of microwave fired samples. Kaolinite dehydroxylation is a 
paradigm, the collapse of kaolinite structure being completely accomplished at $500{ }^{\circ} \mathrm{C}$. Electrically fired samples still show residual kaolinite at $800^{\circ} \mathrm{C}$, although not visible in Fig. 6. The same is observed for talc and muscovite, which structural changes comparatively occur at lower temperatures for microwave firing.
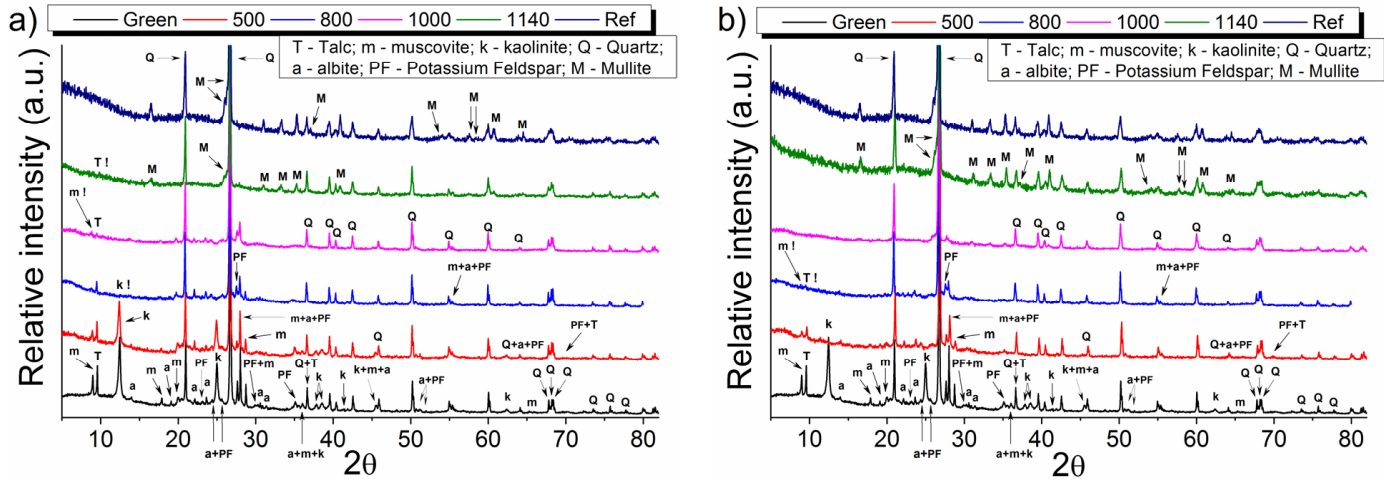

Fig. 6. X-ray diffractograms of aliquots fired at $500{ }^{\circ} \mathrm{C}, 800{ }^{\circ} \mathrm{C}, 1000^{\circ} \mathrm{C}$ and $1140{ }^{\circ} \mathrm{C}$ : a) in electric furnace, and b) in microwave furnace. Dried ("Green") stoneware reference and the gas fired reference ("Ref”) are also presented.

\section{Discussion}

The water absorption analysis shows that aliquots taken from the basal surface of microwave fired mugs provide values below those of the reference; the opposite is observed for the aliquots taken from the mugs rim. This might be related to the temperature differences between the mugs' base and rim, which depends on the heat technology, allowing the higher temperature in the mug's base than in the mug's rim. Since $\mathrm{SiC}$ is a very good microwave absorber, the mug's base contacting the $\mathrm{SiC}$ plate can be at a higher temperature than the mug's rim, and being denser at the base they are less water permeable there.

Microstructural analysis shows that the microstructures of the microwave processed samples are similar to those of the gas reference, for a firing cycle of only $35 \%$ of that required by the reference and for a temperature $\sim 50{ }^{\circ} \mathrm{C}$ lower (Fig. 4). For the same temperatures, the electrically fired aliquots will require more time to reach the same features or characteristics as the reference. Microwave fired samples at $1300^{\circ} \mathrm{C}$ present greater closed porosity, already presenting coalescence and the lost of pores rounded shape. Electrically fired samples at $1300{ }^{\circ} \mathrm{C}$ only show the beginning of the closed porosity growth, still very close to the microstructure of the reference sample.

SEM analysis show that at $1050{ }^{\circ} \mathrm{C}$ there is some feldspar grains dissolution in microwave fired samples, $60{ }^{\circ} \mathrm{C}$ above the formation of the liquid phase at $990 \pm 20^{\circ} \mathrm{C}$ according to [15]. Although it has not been clearly detected through SEM analysis, from XRD analysis it is shown the existence of mullite type- $\mathrm{I}$ in samples fired at $1050{ }^{\circ} \mathrm{C}$, as some peaks characteristic of the presence of mullite in the microwave fired samples are already visible. From XRD analysis, the electrically fired samples at $1140{ }^{\circ} \mathrm{C}$ present mullite peaks less intense than those microwave fired, the last ones having very similar diffractogram to the one of the reference sample. From SEM analysis, at $1140^{\circ} \mathrm{C}$, the mullite is more developed in the microwave fired samples than in the electrically fired ones, already presenting mullite type-II, yet not so developed as in the reference sample. XRD analysis shows also that for temperatures lower than the beginning of the vitrification temperature, some transformations 
occur considerably earlier in the microwave fired samples. Kaolinite dehydroxylation is a case study, already fully accomplished at $500^{\circ} \mathrm{C}$. Electrically fired samples still show residual kaolinite at $800{ }^{\circ} \mathrm{C}$, not observable from the figures. It could be also observed that talc and muscovite structures full transformation and collapse occur for lower temperatures in microwave fired samples than in electrically fired samples.

\section{Conclusions}

Microwave stoneware firing provides similar, or even better, macroscopic features comparatively to those obtained by electrical and gas firing technologies. Microstructure analysis, optical and SEM, provide a better understanding of what was observed on the macroscopic features, microwave fired samples showing more advanced stages of development comparatively to the electrically fired ones, for the same temperatures and/or firing times. DRX analysis shows that some transformations are completed at lower temperatures when microwave firing is used, kaolinite, talc and muscovite transformations being the most notorious cases. The potassium and sodium feldspars seem to completely melt earlier in the microwave fired samples than in the electrically fired ones, presenting less intense peaks. At $1140{ }^{\circ} \mathrm{C}$ the mullite crystals become more developed in the microwave fired samples than in the electrically fired ones, already presenting mullite type-II, with a diffractogram similar to that of the reference sample. The full transformations occur at temperatures closer to those referred to in the literature when microwave firing is used when compared with electric firing.

\section{Acknowledgments}

This work was funded by FEDER funds through the COMPETE 2020 Programme and National Funds through FCT - Portuguese Foundation for Science and Technology under the project UID/CTM/50025/2019. The authors express their sincere thanks to Grestel, Produtos Cerâmicos S.A. (Portugal) and to its staff member Eng. Carlos Pinto for his help and for providing the samples required for this study. The authors also express their sincere thanks to Doctor Manuel Graça from Department of Physics and I3N of University of Aveiro for its help in SEM measurements, to Doctor Maria Rosário from Central Laboratory of Analysis/CICECO of University of Aveiro for its help in the XRD analysis. Author V. A. F. Costa acknowledges the Portuguese Foundation for Science and Technology for the financial support provided through project UID/EMS/00481/2013-FCT, and CENTRO-010145-FEDER-022083.

\section{References}

[1] P. Rado, An introduction to the technology of pottery, Pergamon, 1969.

[2] C. Zanelli, M. Raimondo, et. al, J. Non. Cryst. Solids., 2011, 357, 3251-3260.

[3] Royal Copenhagen, General information about porcelain - Report, n.d.

[4] W.M. Carty, U. Senapati, J. Am. Ceram. Soc., 1998, 81, 3-20.

[5] M.R. Hosseini, A. Ahmadi, Appl. Clay Sci., 2015, 107, 238-245.

[6] R. Wroe, in: IEE Semin. New Dev. Ceram. Manuf., 1998, 1-9.

[7] D.E. Clark, W.H. Sutton, Annu. Rev. Mater. Sci., 1996, 26, 299-331.

[8] D.E. Clark, D.C. Folz, et. al, MRS Bull, 1993, 18, 41-46.

[9] M. Bhattacharya, T. Basak, Energy, 2016, 97, 306-338. 
[10] ASTM C368 e 88, American Society for Testing and Materials, 2011.

[11]BS 5416 - British Standard Specification for China Tableware, 1990.

[12] J.S. Johnson, J. Clark, et. al, J. Archaeol. Sci., 1988, 15, 403-414.

[13] G.W. Brindley, M. Nakahira, Clay Miner. Bull., 1957, 3, 117-119.

[14] Schüller K. H., Porcelain, Ceram. Monogr. - A Handb. Ceram. ,1979, 1-6.

[15] C.R.R. and H.F.M. Ernest M. Levin, Phase diagrams for ceramists, 3rd ed., American Chemical Society, 1964.

[16] H.-Y. Lu, W.-L. Wang, et. al, J. Am. Ceram. Soc., 2005, 87, 1843-1847. 